\title{
Justice and Immigrant Latino Recreation Geography in Cache Valley, Utah
}

\author{
Jodie Madsen \\ Claudia Radel \\ Joanna Endter-Wada \\ Utah State University
}

\begin{abstract}
Latinos are the largest U.S. non-mainstreamed ethnic group, and social and environmental justice considerations dictate recreation professionals and researchers meet their recreation needs. This study reconceptualizes this diverse group's recreation patterns, looking at where immigrant Latino individuals in Cache Valley, Utah do recreate rather than where they do not. Through qualitative interviews and interactive mapping, thirty participants discussed what recreation means to them and explained their recreation site choices. Findings suggest that recreation as an activity done outside the home, for fun with others, leads participants to seek spaces with certain characteristics. Reconceiving recreation more broadly and framing it from the perspective of participants' choices can facilitate clearer understanding of differences and promote greater justice in resource provision and management.
\end{abstract}

Keywords: minority recreation; non-mainstreamed recreation; environmental justice; social justice; Hispanic/Latino recreation

Jodie Madsen completed her master's degree in geography at Utah State University. She is currently the community outreach coordinator at Hyrum State Park in Hyrum, Utah. The research reported here was conducted as part of her master's thesis. Claudia Radel and Joanna Endter-Wada are associate professors in the Department of Environment \& Society, in the Quinney College of Natural Resources at Utah State University. Address correspondence to Claudia Radel, 5215 Old Main Hill, Logan, UT 84322-5215; phone 435-797-0516; claudia.radel@usu.edu. The authors would like to thank all research participants. 
For more than three decades, researchers have studied differences in non-mainstreamed recreation participation, attempting to uncover which constraints have precluded specific groups from engaging in public lands recreation (Byrne \& Wolch, 2009; Floyd, 1998; Gómez, 2002b; Stodolska, Acevedo, \& Shinew, 2009; Washburne, 1978), as reflected in their "underparticipation" in activities that occur in these spaces. Initially, the goal of the research was to determine if those constraints impeded what would otherwise be a large demand for participation, or if recreational differences were due to cultural variations in recreation preferences. More recently, race/ethnicity and leisure research has focused on new areas, with attention paid to ethnic complexity and the intersection of multiple social identities and categories (Shinew et al., 2006) and transnationalism (Stodolska \& Santos, 2006), with a resulting non-essentializing approach to understanding the recreation of non-mainstreamed groups (Arai \& Kivel, 2009; Byrne \& Wolch, 2009).

As a consequence, researchers investigating race/ethnicity and leisure have questioned the utility of comparative analyses that categorize recreationists into distinct groups based on group ethnic or racial identity (Li, Chick, Zinn, Absher, \& Graefe, 2007; Shinew et al., 2006), but arguably, research on recreation difference remains critical to moving into a more socially just future as a nation. Race and ethnicity, although socially constructed categories of difference (Arai \& Kivel, 2009), continue to have practical meaning for U.S. citizens and residents (Floyd, 2007). This article's argument draws on Byrne and Wolch's (2009) synthesis and Young's (2008) work on the politics of difference both to value difference in recreation and to argue for its relevance to social and environmental justice considerations around the distribution of environmental "goods" in society (such as access to recreation resources), the promotion of health and wellbeing across sub-populations, and the facilitation of inter-racial interaction in public spaces.

Historically, environmental justice arose as a topic of activism and scholarship in the U.S. in response to emerging realization that non-White communities bore a disproportionate burden of environmental costs (specifically, pollution) due to the role of race, class, and political power in the siting of hazardous pollution point sources like waste incinerators, as well as due to a widespread geographic correlation of non-White and poor communities with heavily polluting industries (Bryant, 1995; Bullard, 1994; Bullard, Mohai, Saha, \& Wright, 2007). As such, environmental justice concerns were initially linked to health outcomes and risks associated with air and water pollution. In recreation, environmental justice has been similarly linked to health considerations through questions of park access (Byrne \& Wolch, 2009; Floyd, Spengler, Maddock, Gobster, \& Suau, 2008; Joassart-Marcelli, 2010; Stanis, Schneider, Chavez, \& Shinew, 2009) and focused initially on spatial distribution of park resources (Floyd \& Johnson, 2002). In this article, the focus is instead on another important justice consideration-the distribution of benefits in society in terms of perceived use value, including environmental benefits related to access and use of sites provided and maintained for leisure and recreation, even in the absence of health impacts (Roberts \& Chitewere, 2011; Roberts \& Rodriguez, 2008). Thus, this article fuses environmental and social justice perspectives.

Justice considerations dictate that we meet the recreation-related desires of the growing Latino $^{1}$ (or Hispanic) population. U.S. census-designated Hispanics constitute $16.7 \%$ of the nation's population (United States Census Bureau, 2011b). The U.S. Census Bureau predicts that by the year 2050, Hispanics will make up $30.2 \%$ of the total U.S. population (United States Census Bureau, 2008). Previous research has shown that differences between Latinos and the majority Anglo population exist in their observed use of both urban and wildland recreation areas

${ }^{1}$ Latino is used in this paper both as a synonym for Hispanic and to refer to individuals ethnically identifying with Mexico, or Latin countries in Central America, South America, or the Caribbean. 
(Chavez \& Olson, 2009; Scott, Herrera, \& Hunt, 2004) and also in their stated leisure and recreation preferences (Gobster, 2002). Differences do not lead to injustice, but a failure to recognize and value differences, or to manage for varying needs that are based on those differences, do lead to injustice. In the U.S., there is a continued challenge to understand the many dimensions of an ethnically and culturally diverse population and to respond to differences in a manner that enhances environmental and social justice.

The field of recreation geography can contribute to the study of difference in recreation patterns by focusing on where people choose to recreate, as opposed to their failure to conform to majority group patterns and their "under-participation" in specific places or activities (Byrne \& Wolch, 2009). Recreation geographers concern themselves with three basic components of human geography: people, places, and activities. They seek to identify, explain, and predict the spatial patterns of these three elements in order to understand their interactions (Hall \& Page, 2006). In this recreation geography study, we investigate the reasons behind the spatial recreation patterns of the Cache Valley immigrant Latino community (from their perspective). We examine where study participants recreate and why they choose particular sites, with emphasis on the characteristics of the sites themselves and the goals of the recreationists.

With the growth of culturally distinct and politically/socioeconomically disadvantaged ethnic groups comes the challenge of accommodating cultural diversity in a manner that is nondivisive and socially favorable, as well as achieving social justice in access to public resources. For recreation areas throughout the United States, addressing this challenge means finding the most appropriate ways to re-orient and redistribute services to meet the needs and circumstances of a changing society. Therefore, it also becomes essential to understand how ethnic group members conceptualize recreation, which sites are being utilized, and what drives their decisions about recreation. First and foremost, there is a need to better understand the differences underlying observed patterns of differential use (Cronan, Shinew, \& Stodolska, 2008; Roberts \& Chitewere, 2011). With a better understanding of the interaction between the elements of people, place and activity, recreation agencies can enhance strategic plans to "invite, include, and involve" ethnic minorities in recreation (Chavez, 2000), ensure that they are both welcomed and accommodated in all recreation areas, and manage recreation resources to meet their interests. A more complete understanding of where Latinos do recreate and, more importantly, why they go there, will help recreation resource managers meet the needs and expectations of all their visitors.

At the level of society and state, a more productive dialogue is needed around the distribution and fair management of public spaces and of various types of recreation resources. Failure to do so may mean recreation policies and programs will not appropriately reflect the needs of nonmainstreamed ethnic group populations. The result could be a portion of the population that is disconnected from recreation opportunities and important public goods, raising concerns of environmental (in)justice and (un)equal access to the multiple benefits public recreation spaces provide.

The primary objective of the study reported on in this paper was to investigate decision factors for recreation location choices among immigrant Latinos in Cache Valley-where Latino study participants recreate and why-utilizing a combined and innovative qualitative interview and mapping procedure. Latinos in Cache Valley are still a relatively small proportion of the population (10\% in 2010, see United States Census Bureau, 2011a), but this proportion is growing (from 6\% in 2000). As a less visible community within the Valley, there is perhaps greater expectation that this community should simply "acculturate." Local recreation resource managers, on the other hand, recognize a need to understand and respond to Latino recreation needs, 
but are unclear on how to proceed, which provided an applied research rationale. From a more generalizable research perspective, this study also presented the opportunity to examine what recreation choices Latinos in Cache Valley make, given the range of opportunities, from national public land to state and local parks to private recreation facilities. Unlike the sites of much previous relevant research, Cache Valley remains largely rural, surrounded by public lands, especially National Forest, and is heavily oriented to the dominant culture of hunting, fishing, camping, hiking, ATV use, and skiing.

\section{Literature Review}

\section{Race/Ethnicity and Recreation: An Overview}

Major research emphasis on non-mainstreamed recreation patterns began in the 1970s. The early work largely discussed causes for low or non-participation of different racial and ethnic groups in recreation activities traditionally engaged in by the mainstreamed White population. In attempts to explain differences, previous research took a decidedly White-conformist perspective. This research endeavored to identify the barriers that kept specific populations from recreating in ways similar to the White mainstreamed population. Several theories emerged from this work; the two most prominent became known as the marginality and ethnicity theories. Fast growth in the Latino population prompted more recent studies (Chavez \& Olson, 2009; Scott et al., 2004) to center on recreation activities by that segment of the population, at the same time that the literature began to expand in response to questions raised about "under-participation" of non-White populations (Floyd, 1998). More recent research on the intersection of race and ethnicity in recreation patterns has moved away from using group social identities to categorize individuals and from examining differences based on these categories, and instead focuses on the construction of social identity within and through recreation (Arai \& Kivel, 2009; Erickson, Johnson, \& Kivel, 2009; Mowatt, 2009).

Despite movement in the literature beyond the marginality and ethnicity theories, these theories continue to hold sway in recreation-related public policy and land management and, as such, merit a brief review. The marginality theory suggests the general marginal position of non-mainstreamed ethnic and racial groups in society is a result of external, preventive factors. As Washburne (1978) summarized, these factors include a lifestyle constrained by unmet basic needs (poverty), poor transportation, and limited opportunities due to an urban "ghetto" residence. The marginality theory encompasses the idea that both historical and present racism and discrimination serve as barriers and constraints to equitable recreation participation (Blahna \& Black, 1993; Floyd, 1998). The ethnicity theory contends leisure is a reflection of culture and that there are inherent differences in cultural values and norms that influence recreation choices. Under this theory, normative and perceptive values maintained by non-mainstreamed groups can be affected by a variety of elements and be passed down over time. For example, research focused on investigating social organization implies that social group organizational differences, such as the traditional family-oriented culture of Mexican-Americans, may help explain differences in recreation choices between this subpopulation and the mainstream White population (Hutchison \& Fidel, 1984). Over time, ethnicity and marginality theories were combined as the best avenue for explaining why differences exist in recreation patterns: differences in social marginality status and ethnic preferences lead to a complex interaction of intrapersonal, interpersonal, and structural constraints affecting recreation behaviors (Crawford, Jackson, \& Godbey, 1991; Gómez, 2002b; Juniu, 2000; Scott et al., 2004). In particular, Gómez (2002b) introduced the 
"Ethnicity and Public Recreation Participation Model," which draws upon a wide variety of variables, previously overshadowed in the marginality and ethnicity debate, to understand and model individual recreation behavior, through an emphasis on perceived benefits. Marginality and ethnicity may be inextricably linked as the marginal position of non-mainstreamed ethnic groups in a society, especially over time, shapes the norms and values of the group.

\section{Wildlands Recreation versus Urban Parks Recreation}

Another distinction made in leisure and recreation research affects researchers' ability to speak to the broader realm of activities people engage in for relaxation or during their "free time." Much of the research has focused on one of two categories of recreation: urban or wildland. Many researchers have taken a forest-centered or public-land approach and investigated why particular ethnic or racial groups do not frequent wildland recreation areas or participate in wildland recreation activities on U.S. national forests, parks and other public land in proportion with their population in society (Carr \& Williams, 1993; Floyd \& Gramann, 1993; Scott et al., 2004; Washburne, 1978). However, given their focus on wildlands, practically none of these studies asked where the participants actually were recreating, if not in wildlands. The urbanwildland distinction within the literature has contributed to a focus on "under-participation" and implied a need for conformity with mainstreamed culture-a problem from a social justice perspective due to the failure to recognize cultural difference and the tendency to frame issues in terms of majority-minority paradigms (Young, 2008).

Research more specifically focused on wildland recreation behaviors of Latinos within the national forests found survey respondents consistently rate the availability of amenities as important or very important, or otherwise desire the development of recreation sites (Chavez, 2002; Chavez \& Olson, 2009). Other studies support these findings as well, indicating Latinos recreate at sites where picnic opportunities exist, especially those with access to water either for activities or scenery (Chavez, 2001; Sasidharan, Willits, \& Godbey, 2005). Researchers also have documented the importance of places that can accommodate families and large groups, often for team activities like playing soccer, or picnicking and intergenerational socializing. As Carr and Chavez (1993) found, group differences also often exist within seemingly uniform activity categories. For example, picnicking for Latinos was found to be an all-day event including onsite preparation of meals and almost always to include nuclear and extended family members. While these studies emphasized wildland recreation among non-mainstreamed members, they did attempt to identify the factors influencing choices of particular sites within these settings.

Investigations into race/ethnicity and leisure also were conducted on urban park use beginning in the early 1970s. Since then, many other studies have attempted to explain the role of urban parks as recreation places for non-mainstreamed ethnic and racial groups (Blahna \& Black, 1993; Hutchison \& Fidel, 1984; McMillen, 1983; West, 1989). This line of research generally concluded social organization, racism, and isolation from White culture explains nonWhite group preferences for urban parks and recreation areas. However, this research has rarely asked what amenities, specific to the urban recreation space, draw participants there instead of to other places. Other researchers, including geographers, have continued to examine the uneven spatial distribution of urban parks and open space areas as an environmental justice concern (Boone, Buckley, Grove, \& Sister, 2009; Sister, Wolch, \& Wilson, 2010; Joassart-Marcelli, 2010).

\section{Defining Recreation and Leisure for Others}

An often overlooked critique of recreation research on non-mainstreamed groups is that researchers frequently assume everyone in a study has the same understanding and definition of leisure (Parr \& Lashua, 2004) or recreation, and researchers' definitional distinctions between 
recreation and leisure activities are reflected in the actual practice of recreationists. Evidence suggests ethnic identity plays a role in shaping the meaning of recreation, which varies with people's singular or mixed subcultural identifications (Gómez, 2002a; Parr \& Lashua, 2004). Therefore, when trying to understand the greater landscape of recreation patterns, unique insights can be gained when respondents are allowed to define for themselves what that recreation includes, which may involve activities that some researchers would tend to categorize as "leisure."

\section{Immigrant Populations and Leisure}

A relatively smaller subset of literature within recreation and leisure studies examines the recreation behavior of more recent immigrant populations in the U.S. Stodolska and Alexandris (2004) found immigrants in their study had initially low levels of participation in sports recreation, followed by later variation in whether or not they acculturated to mainstream patterns, to existing non-mainstream patterns, or maintained distinct patterns. Stodolska and Yi (2003) demonstrated that recreation and leisure patterns change following immigration, as immigrants form ethnic identity within the context of their new country of residence. Stodolska (2000) found that these changes reflect past latent demand, changes in constraints, and exposure to new opportunities. In Gómez's (2002b) "Ethnicity and Public Recreation Participation Model," acculturation is an important factor in predicting recreation participation, including among Latinos, but in combination with factors associated with ethnicity, marginality, and discrimination (Gómez \& Malega, 2007). Stodolska and Walker (2007) reviewed much of this research and argued we need to distinguish these populations from other established ethnic groups in the U.S. and better understand their recreation decisions, given immigration trajectories.

\section{A Framework for this Study}

This brief review indicates that differences, based on social identities, including race and ethnicity, continue to play key roles in discussions about non-mainstreamed recreation. Feagin (2007) distinguished between the two terms as belonging to a social group set apart based on physical characteristics (race) or cultural or nationality characteristics (ethnicity). Both physical and cultural characteristics can serve as the basis for unequal structural positioning of power within a society and unequal treatment (Floyd, 1999), and race and ethnicity are often linked and simultaneously constructed. A politics of difference, vis-à-vis public policy, asserts that identification and social construction of difference (group belonging/exclusion marked by race, ethnicity, and other social groupings) needs to be acknowledged and addressed in policy design, development, and implementation (Schneider \& Ingram, 1997). Young (2008) described two different lines of thought in this regard: (a) positional difference and (b) cultural difference. A politics of positional difference upholds that social processes position people and social groups along social axes, creating inequalities in power, status, and opportunity. A politics of cultural difference posits that some groups face distinctive issues simply due to what defines them as a societal culture, such as nationality. Young argued that since societies today consist of at least two cultural groups, and one of these cultural groups dominates the polity, a politics of cultural difference frames the requirements of justice in terms of accommodating and recognizing cultural diversities. She argued that in order for public policy to address social difference, it must consider both positional and cultural differences. Schneider and Ingram (1997) illustrated how these differences, if not explicitly acknowledged, can become embedded in policy designs and reinforced over time. 
By focusing on the geography of immigrant Latino recreation in Cache Valley, Utah, we endeavor to build upon a history of research that highlights the intersection of the marginality and ethnicity explanatory theories, and to add to the current expansion of this body of research. Recreation geography helps us explore the diverse patterns and processes associated with recreation across a larger landscape (Smith, 1983), and to extend the discussion beyond forests versus city parks, allowing participants to define recreation as they perceive it and identify locations that, for them, constitute appropriate recreation sites. In this study, we attempt to uncover what immigrant Latino recreation is rather than focus on what it is not. While acknowledging the diversity of experience within the research population, we nonetheless attempt to identify commonalities of experience that can inform a more just leisure and recreation policy and management approach that recognizes the potential for group difference based on politically and socially meaningful categories of race/ethnicity.

\section{Methods}

\section{Research Location}

Cache County, Utah has experienced a 94\% increase in Latinos from 2000 to 2010. Latinos now make up $10 \%$ of the population, by far the county's largest non-mainstreamed ethnic group (United States Census Bureau, 2011a). Cache County, also often referred to as Cache Valley ${ }^{2}$, incorporates approximately 26 different communities, but most Latinos live in the cities of Logan and Hyrum. With the increasing Latino population, community access issues are beginning to garner public attention. For example, in 2007, Latinos made up only $6 \%$ of the visits to the nearby Wasatch-Cache National Forest (USDA Forest Service, 2010). Public and private recreation opportunities abound in Cache Valley, making it an ideal site to explore how various places are chosen and utilized by the growing Latino population. Within the County's borders are a variety of recreation opportunities found at federal, state, and municipal sites. Cache County also offers a wide variety of private indoor and outdoor recreation options, from skiing to indoor rock climbing, and bowling to horseback riding.

\section{Participant Selection}

Participants in this study were a convenience sample from within the immigrant Latino community of Cache Valley. Thirty in-depth interviews were conducted in 2010 and Table 1 conveys the basic respondent demographic information revealed through observation and responses to interview questions. Respondents were all first-generation immigrant residents with varying levels of English ability. Twenty-four of the participants preferred to have the interview conducted solely in Spanish, with four preferring English, and two using a mixture of both languages. The ages of participants ranged from their early 20 s to their 60 s. Participants were engaged in a variety of occupations, including university students, business owners, and day laborers. Although this was not a random sample survey, the characteristics of the participants are indicative of the relatively new, diverse, and growing demographic status of the Latino community in Cache County.

Research procedures. Researchers employed an exploratory, qualitative approach based on grounded theory, a strategy often used when a researcher is attempting to understand the view of participants and to describe meanings of actions from their perspective (Corbin \& Strauss,

${ }^{2}$ Cache Valley is technically in both Cache County, Utah and Franklin County, Idaho. Cache County covers only the southern portion of the valley which is also where the population is concentrated. 
2007; Creswell, 2009; Glaser \& Strauss, 1967; Neuman, 2009). Semi-structured interview questions asked while viewing and recording information on an area map aimed to uncover three essential elements: how participants conceptualize recreation (in order to recognize and valorize cultural difference); how participants operationalize recreation choices through places they visit and do not visit (in order to understand local site use patterns); and, what participants view as the greatest influences on their recreation choices (in order to identify any management and access concerns and to confirm findings in the existing literature, based on research elsewhere). The combined interview and mapping procedure was the conversation tool for talking about the larger geographic landscape in which people make leisure and recreation choices and for assessing participants' knowledge of and decisions about sites to access and utilize.

\section{Table 1}

Demographics of Respondents ( $n=30)$

\begin{tabular}{lcc} 
& \# of respondents & $\begin{array}{c}\% \text { of total } \\
\text { respondents }\end{array}$ \\
\cline { 2 - 3 } Gender & 21 & $70 \%$ \\
Female & 9 & $30 \%$ \\
Male & & \\
\hline Marital status & 23 & $77 \%$ \\
$\quad$ Married & 7 & $23 \%$ \\
$\quad$ Not married & & \\
\hline Parental status & 25 & $83 \%$ \\
Has children & 5 & $17 \%$ \\
No children & & \\
Language of interview & 24 & $83 \%$ \\
Spanish & 4 & $10 \%$ \\
English & 2 & $7 \%$ \\
Mixed Spanish/English & & \\
\hline Country of origin & 21 & $70 \%$ \\
Mexico & 2 & $7 \%$ \\
Guatemala & 2 & $7 \%$ \\
Venezuela & 2 & $7 \%$ \\
Peru & 1 & $3 \%$ \\
El Salvador & 1 & $3 \%$ \\
Uruguay & 1 & $3 \%$ \\
Dominican Republic & 6 & $20 \%$ \\
\hline Length of residency in the U.S. & & $33 \%$ \\
20-29 years & 10 & $47 \%$ \\
10-19 years & 14 & \\
0-9 years & & \\
\hline Averge & & \\
\hline
\end{tabular}

${ }^{\mathrm{a}}$ Average length of residency for interviewees was 12 years.

The study was conducted in two phases. A preliminary and minor phase focused on interviewing recreation public officials for their general observations of local Latino recreation patterns. Six key informant interviews were conducted with public officials from recreation management agencies in Cache Valley including the Wasatch-Cache National Forest, Hyrum State Park, Logan Parks and Recreation, and Hyrum Parks and Recreation. Following these interviews, 
a core phase of the research focused on local Latinos and their perspectives on their own behaviors. Choosing not to focus on one predetermined recreation type (e.g., outdoor, wildland) or recreation site (e.g., national forest, city park) allowed the study to maintain its exploratory focus and respond to the identified need from the literature to understand how Latinos in the study define recreation and utilize recreation spaces. Data collected during this core phase were the foundation for this article's analytical focus. The 30 semi-structured and tape-recorded interviews lasted approximately 60 minutes each, and interviewees were prompted to reflect on their views and decisions regarding recreation for themselves and their families. As participants spoke about their recreation activities, maps of the Valley were used to mark locations that they identified and discussed. These maps functioned as a participatory interview tool, providing a point of focus for the interviewee and a material object around which to interact.

The individual interviewee maps were compiled into one aggregate map in order to conduct a simple visual analysis of locations utilized by participants. ${ }^{3}$ Clear groupings of sites visited by multiple respondents were revealed, showing which sites were the most commonly mentioned and their locations compared to each other (see Figure 1). This mapping process also aided in an analysis of the dispersal across the Valley of recreation places used by interviewees. Every site mentioned was later categorized by researchers according to the management/tenure agency that oversees it, as either a federal, state, municipal, or private recreation site. Counting how many respondents mentioned sites within each of these four categories revealed the management/ tenure diversity in types of sites that are visited by participants, as well as how common these responses were among participants. Open-ended responses from the semi-structured interviews received another type of analysis: Each interview transcription was reviewed and the information was coded and organized based on common themes that occurred within and across the interviews. This article focuses on the portion of the data regarding the meanings ascribed by participants towards their recreation, the location of their recreation, and the reason for recreation at a specific site.

\section{Results/Findings}

\section{Manager Perspectives and Observations}

Interviews with two national forest managers, a state park manager, and three city recreation managers revealed all three managing agencies experienced an increase in usage of their sites by Latinos, more specifically usage of outdoor sites with developed facilities. These managers of local public sites perceived that Latinos prefer large group capacity, day-use facilities with areas sufficient enough to allow picnicking and/or participation in sports activities (specifically soccer or basketball). State park and national forest managers reported visits to their sites by Latinos increased significantly on Sundays and focused on use of water resources, almost exclusively for fishing from the banks, and often included family picnics. While both the national forest and state park agencies maintain numerous campsites and hiking trails, managers state that nearly all users of those recreation amenities are Anglo. Logan City Parks and Recreation managers also

${ }^{3}$ Similar individual and aggregate maps were created for recreation locations not used by participants (both sites participants did not wish to use and those that they did). In this article, we only focus on the recreation sites used by participants. For a discussion of sites not used by this study's participants, see Madsen, Radel, and Endter-Wada (2013). 

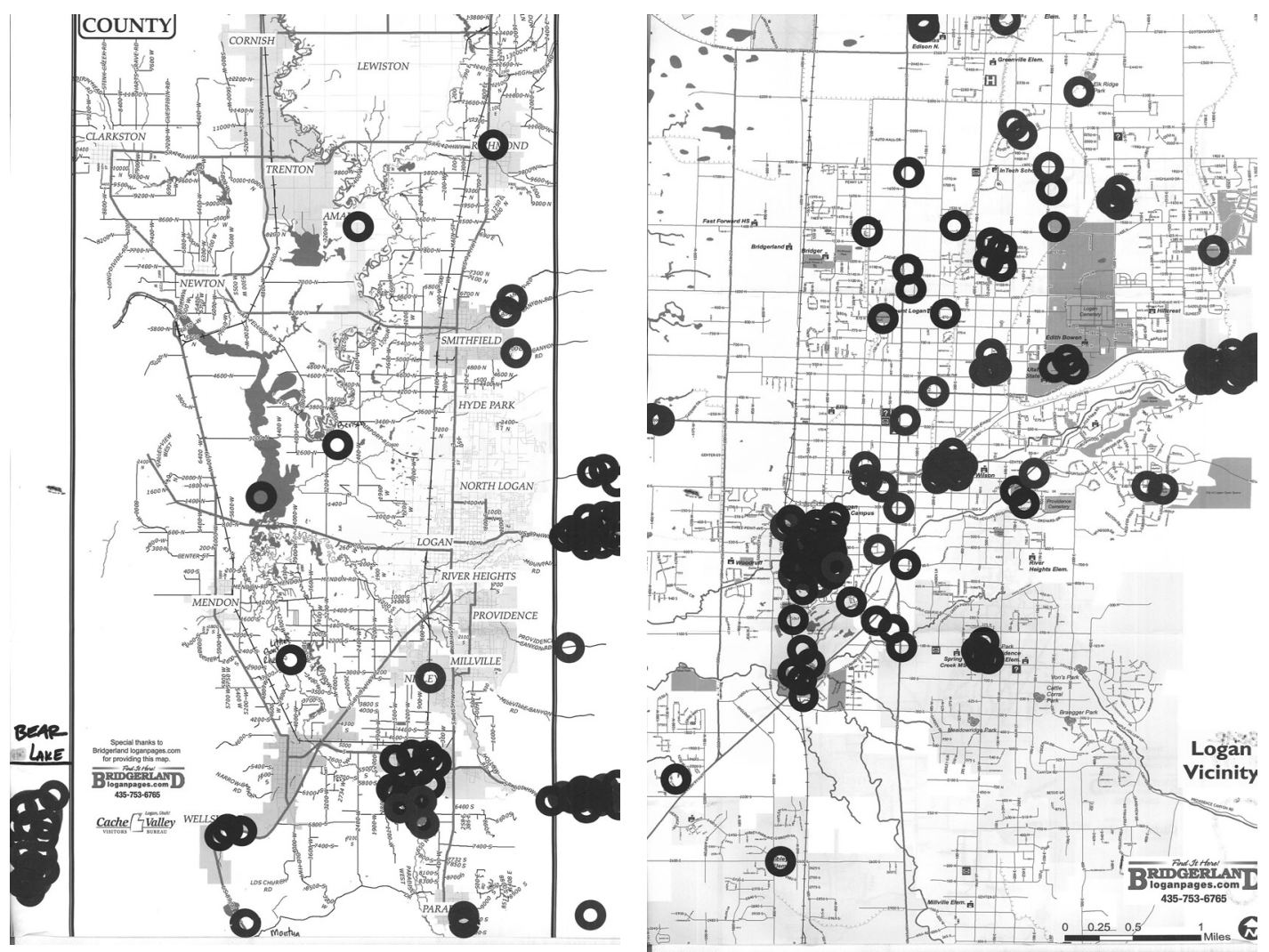

Figure 1. Composite maps constructed from individual maps with visited sites marked during interviews (Logan City vicinity on left and Cache County on right)

commented on the extremely low participation by Latinos in the Logan-based Recreation Center programs and city-organized recreation leagues.

In 2008, the county Hispanic Health Coalition conducted a focus group to investigate what the Latino population knows about the Logan City Parks and Recreation programs and facilities. They found the Latino population is generally uninformed about Logan's recreation programs and facilities, and that time, money, language, and geographic location of the Recreation Center may preclude participation in some programs. Information from this focus group was made available to city officials who expressed interest in better understanding needs of the Latino portion of the population. However, according to the managers interviewed in this study, little had been done by the national forest, state park, or city recreation agencies to reach out specifically to Latino residents because managers felt their recreation desires were being met. ${ }^{4}$

\section{Latino Resident Interviews}

Conceptualization of recreation. When local Latino respondents were asked to provide their personal definition of recreation, seven key characteristics were mentioned that frame interviewees' conceptualizations of recreation. For the respondents in this study, recreation is defined as one or more of the following: (a) fun/enjoyment, (b) being with others/family,

${ }^{4}$ This situation has changed since the study was conducted. Following completion of her graduate degree, the first author was hired by Hyrum Lake State Park to coordinate outreach to the Latino community. 
(c) being outside the home, (d) rest/relaxation, (e) an activity done outdoors in fresh air, (f) a planned activity, or (g) a physical activity.

Three characteristics in participants' definitions were most commonly mentioned. Fifteen of the 30 participants' definition (50\%) included a statement that recreation was specifically done for fun or enjoyment. Nearly as common were the statements that recreation is something done with others, most often family (46\%), and that recreation is done away from their home (including both indoor and outdoor locations) (46\%). For some respondents, all three characteristics made up their definition of recreation, illustrated by the statement, "Recreation for me is going out... to have fun... to do activities with family or with friends." However, for some respondents, one of the characteristics took priority in their definition of recreation, just as this man explained: "More than anything, it's the time that one can spend with people, whether it's family or people you have fun with, friends, etc. Being alone isn't really in my definition of recreation."

Recreation defined as rest or relaxation was mentioned by nine of the participants (30\%), often indicating that it was to help de-stress. One participant explained: "[Recreation is] something outside of work that you do to kind of relax and enjoy. [It is] something fun and it doesn't have to be physical or anything, it can also just be to quiet the mind."

Six of the 30 respondents (20\%) stated recreation was defined as only taking place outdoors or in the fresh air, or "aire libre," with one participant describing it this way: "I don't think of it so much as in the house. I see it as outside. It's always in fresh air." Less commonly mentioned, but still an important aspect of their definition of recreation for four of the participants (13\%), was that recreation is something that must be planned, or as a respondent stated, "designating the time for recreation, like planning it."

While most of the respondents indicated recreation could include physical activities like sports, for only two of the participants $(7 \%)$ did the definition of recreation require a physical element. One participant explained, "Recreation is going out on walks or [bike] rides..... physical activity." For the majority of respondents in this study, recreation did not mean engaging in specific activities in specific places, but was more about gathering with friends or family outside the home and having fun. Due to this broader definition of recreation, some respondents (but not all) included sites such as movie theaters, stores, and churches in their subsequent interview discussion of recreation sites.

Mapping activity and site categorization: where do study participants go? By marking locations on maps during the individual interviews and then compiling all the individual maps into one composite map, clear patterns emerged that revealed which sites are visited for recreation by multiple respondents. Three Logan City parks (Willow Park, Merlin Olsen Park, and Canyon Entrance Park) are visited by the greatest number of respondents. Other municipal sites also dominated the respondent recreation scene. Although half of the respondents live in Hyrum City, which is located approximately nine miles south of Logan City, the same three Logan City parks were most commonly mentioned by all participants. The park visited by the greatest number of respondents (Willow Park-see Figure 1) is also the park located in an area of town with the greatest geographic concentration of Latino residents in Logan City.

Other clusters became apparent through the mapping activity, indicating Logan and Blacksmith Fork Canyons, which are part of the larger Wasatch-Cache National Forest system, are popular destination choices for many respondents. However, the sites most commonly mentioned were those clustered around the mouths of the canyons on the border between the cities (Logan and Hyrum) and the National Forest. Two of these sites are parks maintained by the parks and recreation departments of the cities of Logan and Hyrum. Sites in the National 
Forest that were most mentioned are picnic areas with access to water near the small dams along Logan River or the Blacksmith Fork River. Lakes were also revealed to be popular places for respondents with definite clusters forming around Hyrum Lake State Park and Bear Lake.

A simple analysis of the location map created by combining all the individual participant maps shows that while sites visited for recreation are located all over Cache Valley, the sites most utilized are relatively close to each other. Although Cache Valley is not an urban county with high population density and has free bus service that makes travel around the Valley quite easy, the three places most often mentioned by participants during the mapping exercise are all located within four miles of each other. The two furthest places mentioned other than Bear Lake ${ }^{5}$ (and each of these was mentioned only once), are located a full 28 miles from each other.

For analysis purposes, researchers also assigned a management/tenure category (municipal, state, federal, and private) to each site mentioned during the interviews, then identified which of the four categories of sites each interviewee used for recreation. Table 2 compares prevalence of use for the four management/tenure categories of sites mentioned by the participants, and Table 3 details the frequency of mention for specific sites within those categories.

\section{Table 2}

\section{Types of Sites Visited by Respondents ( $n=30$ )}

\begin{tabular}{lcc}
\hline $\begin{array}{c}\text { Management or } \\
\text { tenure category }\end{array}$ & $\begin{array}{l}\text { Respondents visiting at } \\
\text { least one site in category }\end{array}$ & \% total respondents \\
\hline Municipal & 30 & $100 \%$ \\
State & 22 & $73 \%$ \\
Private & 18 & $60 \%$ \\
Federal & 17 & $57 \%$ \\
\hline
\end{tabular}

All 30 participants (100\%) indicated they had used municipal recreation sites at least once while living in Cache Valley. City parks, including the Willow Park Zoo, dominate as the kinds of sites visited within the municipal category. In addition to city parks, several other municipal sites were mentioned by many respondents. While a great diversity of municipal sites was mentioned, no one particular site was mentioned with regularity other than specific city parks. State recreation sites, especially Bear Lake and Hyrum Lake State Parks, were also a common type of site utilized, with $22(73 \%)$ of the respondents indicating they had visited one of those sites at least once. Visits to federal recreation sites were the lowest reported category. Seventeen of the 30 participants (57\%) indicated they had used a federal site at least once. The most popular use of federal sites involved the National Forest picnic areas and campgrounds located just off of Highway 89 in Logan Canyon. Smithfield, Blacksmith Fork, and Green Canyons were also mentioned as sites within the federal category, but were associated only with picnicking, not with camping. Use of private business recreation sites was about equal with the use of federal sites. Of the 30 participants, 18 (60\%) indicated they had visited a private site at least once. This category had the most diversity according to the kinds of recreation places. The business mentioned most often

${ }^{5}$ While Bear Lake is not located in Cache Valley, it was mentioned by many of the participants as a yearly recreation destination so it was included in the study within the state recreation category. It is omitted from the location map analysis because of its distance from the rest of the recreation sites in Cache Valley. 


\section{Table 3}

\section{Sites Visited by Study Participants ( $n=30$ )}

\begin{tabular}{|c|c|c|}
\hline $\begin{array}{l}\text { Management or tenure } \\
\text { category }\end{array}$ & Recreation Site & $\begin{array}{l}\text { Respondents } \\
\text { visiting site }\end{array}$ \\
\hline \multirow[t]{17}{*}{ Municipal } & Canyon Entrance Park ("First Dam") & 20 \\
\hline & Other municipal parks (12 different parks) & 20 \\
\hline & Willow Park & 18 \\
\hline & Willow Park Zoo & 14 \\
\hline & Fairgrounds & 10 \\
\hline & Merlin Olsen Park & 8 \\
\hline & Hyrum Canyon Park & 8 \\
\hline & Logan Aquatic Center & 8 \\
\hline & Adams Park & 7 \\
\hline & Golf courses ( 2 different ones) & 4 \\
\hline & Logan Recreation Center & 3 \\
\hline & Logan River Trail & 3 \\
\hline & Town festivals and parades & 2 \\
\hline & Logan Skate Park & 2 \\
\hline & Ellen Eccles Theater & 2 \\
\hline & Public school facilities (pool and grounds) & 2 \\
\hline & City libraries and museums & 2 \\
\hline \multirow[t]{4}{*}{ State } & Bear Lake State Parks & 22 \\
\hline & Hyrum State Park & 13 \\
\hline & $\begin{array}{l}\text { Utah State University indoor facilities (anthropology museum, } \\
\text { theater and concert venues) }\end{array}$ & 6 \\
\hline & Utah State University "Old Main Hill” green space & 3 \\
\hline \multirow{12}{*}{ Federal } & National forest trails (non-canyon specific) & 15 \\
\hline & Logan Canyon picnic areas and campgrounds & 14 \\
\hline & Fishing areas & 11 \\
\hline & Blacksmith Fork Canyon & 10 \\
\hline & "Second Dam" recreational area & 7 \\
\hline & Other canyon trails/recreational areas ( 4 canyons) & 6 \\
\hline & National Forest (general) & 6 \\
\hline & Other National Forest campgrounds & 5 \\
\hline & Other National Forest picnic areas & 4 \\
\hline & Hardware Ranch Wildlife Management Area & 3 \\
\hline & "Third Dam" recreational area & 2 \\
\hline & Other federal land & 3 \\
\hline \multirow[t]{11}{*}{ Private } & Indoor arcade, skating, bowling, and soft play business & 12 \\
\hline & Stores/shopping and restaurants & 7 \\
\hline & Movie theaters & 6 \\
\hline & Church & 4 \\
\hline & Bowling alley & 2 \\
\hline & Fitness gym & 2 \\
\hline & Ice rink & 2 \\
\hline & Rock climbing gym & 1 \\
\hline & Beaver Mountain Ski Resort & 1 \\
\hline & Shooting range & 1 \\
\hline & American West Heritage Center & 1 \\
\hline
\end{tabular}

was the Cache Valley Fun Park, an indoor arena with roller skating, bowling, an arcade, laser tag, and other activities.

An important insight comes from the references to the types of sites utilized primarily during the winter, which in Cache Valley generally lasts for six months out of the year, roughly from November through April. Throughout the 30 interviews, winter-related activities and sites were mentioned by only six people (20\%). Sled hills, the local ski resort, a snowshoe and crosscountry trail, and the occasionally operational outdoor ice rink at one of the city parks were the only outdoor winter recreation sites participants indicated they had visited. These sites cross all four previously described categories (municipal, state, federal, and private). Twenty-four ( $80 \%$ ) 
of the respondents indicated summer is the primary season for their visits to recreation sites. One participant voiced a common sentiment among respondents: "I came from a country that's really warm, so I can't bear the cold. I don't like it much, so I prefer to stay in my house." Several respondents mentioned indoor winter recreation sites, with either the movie theater or the Cache Valley Fun Park being the only recreation sites they visit in the winter.

Desired site characteristics: Why do respondents visit particular sites? In order to construct better within-group understanding, we sought to focus less on explaining how and why Latino recreation was different from Anglo recreation (hence the absence of a Anglo comparative group), and more on where and why Latinos choose to recreate. Therefore, development of common themes uncovered during analysis of the 30 interviews centered primarily on characteristics of the locations that explain why respondents visited those particular places. These site characteristic "decision factors" are those elements that respondents described as attractive and which drew them, often repeatedly, to particular recreation sites.

The analysis of "decision factors" resulted in the development of six categories indicating why respondents visited their chosen recreation locations: (a) facilities available, (b) family suitability, (c) scenery present, (d) activity desired, (e) seclusion of site, and (f) proximity to home (Table 4). These themes identify various physical characteristics and elements associated with the recreation site itself.

\section{Table 4}

Recreation Site Desired Characteristics ( $n=30)$

\section{Respondents identifying characteristic as important to site choice}

$\%$ total respondents

\begin{tabular}{lcc}
\hline Facilities available & 24 & $80 \%$ \\
Family suitability & 22 & $73 \%$ \\
Scenery present & 19 & $63 \%$ \\
Activity desired & 19 & $63 \%$ \\
Seclusion of site & 11 & $37 \%$ \\
Proximity to home & 9 & $30 \%$ \\
& \\
\hline Note. We use the term facilities here, instead of amenities, for the first listed characteristic. We prefer facili- \\
ties because we feel it more accurately reflects what the interviewees identified, and as we see amenities as a \\
broader category. Some of our other characteristics (e.g. scenery) can also been seen as amenities.
\end{tabular}

Facilities. Facilities provided at the recreation location proved to be an important characteristic for respondents. Of the 30 participants, 24 (80\%) indicated they visited at least one of their recreation locations because of its developed facilities. These recreation locations included sites from all four management/tenure categories, and referred to such facilities as bathrooms, children's play sets, BBQ grills, pavilions, tracks or trails, water fountains, campgrounds, and open fields for sports. As described by one participant: "We look for a place where everything is ready. We pay... a little money, and they let us in and they have all the services. We like places where there are all the services." Regarding fishing locations, another respondent described it this way: "It's kept up really clean by the Forest Service...there's a restroom there for the kids and the family can use it. There's a little grassy area where the kids can run around and we enjoy that." 
Sites visited within the National Forest are almost entirely the developed sites, often for camping or picnicking, with bathrooms, tables, and fire pits. Therefore, physical development of sites and facilities built on those sites are important characteristics of recreation locations for participants in this study. Of all respondents, only three mentioned using the forest in less developed areas, one for hiking, one for camping, and one for riding ATVs.

Family suitability. Family suitability also emerged as highly important; 22 interviewees (73\%) indicated they choose certain places because they can take their family there. This most often referred to the participant's own children or grandchildren and meant the location provided something beneficial to children in particular. As one grandmother put it:

I think the kids feel good, that they feel free to run here and there...They can climb trees that one doesn't have at home, and there's space for the whole family. They also can get together with other kids and make friends.

Another respondent spoke of a developed trail near the mouth of Logan Canyon: "We can go as a family, some on bike and others walking. [But not hiking or climbing up]...just simple and easy." Still others gave responses indicating the location was visited because it could accommodate extended family get-togethers, such as birthday parties or family picnics. "I love it there because...it's big. It's one we choose for the whole family."

Scenery. Scenery proved to also be a popular characteristic as 19 participants (63\%) indicated they choose recreation locations that provide some kind of scenic aspect, including animals, plant life, water, fresh air, and attractive views. As one woman put it, "You can go and discover nature." Another spoke of scenery this way: "I like it because it's fresh, there's a lot of air because there are plenty of trees. And one can relax by the water too. There's a lot of space." Water in particular was a popular scenic element for respondents, as they indicated having a stream flow by or watching the water while sitting along the banks of a pond or lake was a particular draw for them.

Activity desired. Water also played an important role in some participants' preferences in recreation location because of specific activities it could support. This theme or classification of activity desired is based upon comments by 19 (63\%) participants indicating they choose some of their recreation places because they contain designated areas for specific activities in which they like to engage. These included soccer fields, volleyball and basketball courts, fishing ponds, museums and historical sites, and (for a few) skiing and ATV trails. One respondent indicated that she accompanied her husband to a site he used for fishing but that she also had specific activities in mind, saying, "I love getting wet myself, that's why I always go where there's water. That's basically where I go: the water or the volleyball court." A different respondent spoke of the historical sites and museums scattered across the Valley as a means of education, commenting, "If I live in a city, I go to visit the museum to inform myself."

Seclusion. The fact that some places provide an element of seclusion is also of some import. Just over a third of the respondents (11) identified that being able to go "somewhere less crowded," "distanced from the city," where there is "less noise" and where "one can relax" were characteristics that drew them to those places. Regarding the city park inside Logan City, but on the border near the mouth of Logan Canyon, one participant described it this way: "It's a place, for me personally, where I can go to feel peace outside of the city." Yet another spoke of seclusion in terms of its relaxation properties: "Going to the canyon there's lots of trees and one can go de-stress."

Proximity to home. While not as commonly mentioned by respondents, proximity to home is still an important characteristic, as nine of the 30 respondents (30\%) said that they choose 
some locations because they are close to their house and they can easily access these sites. "A lot of the time we choose this place because if something were ever to happen, we're close to home; we're not too far." Another study participant spoke of a trail near the golf course in her neighborhood saying, "It's really close; we get there by walking."

\section{Discussion}

By one definition, recreation is what we do when we are free to choose (Broadhurst, 2001). Allowing each participant to determine the scope of "recreation" for him- or herself, and respond accordingly, this study captured some of the key elements important to participants' conceptualization of recreation and identified the prevalence of those elements among all the respondents. Much as Gobster (2002) found from a quantitative survey enumerated in an urban park context, this study identified significant choice diversity among study participants. Nonetheless, we also identified some commonalities. Our main finding is that, for many people in this group of respondents, recreation entails seeking space to gather with others, relax, and have fun.

In addition, the data produced from the in-depth interviews and mapping exercise utilized in this study suggest that recreation activities are not conceptualized as inherently distinct from leisure activities by the study's Latino participants but are, in many respects, one and the same. In defining recreation and choosing sites to utilize, many respondents, for example, discussed both park use and movie theater use, suggesting they do not conceive of these sites as being in separate categories. This finding bolsters Parr and Lashua's (2004) argument that concepts such as "leisure" can vary between groups, here applying it to the concept of "recreation."

How recreation objectives map to specific recreation places or sites in a geographic context (in this instance, Cache Valley, Utah) is critical to the discussion of the landscape of recreation. While opinions differed as to the kind of place in which recreation could occur (i.e., whether it included indoor and outdoor spaces equally), it becomes obvious when looking at the places these participants visit that recreation does not generally include wild or undeveloped outdoor spaces, and does not include the outdoors in winter. Although the preferences for recreation sites with scenery, facilities, and family suitability among many of the Latino participants in this study are consistent with previous research (Baas, Ewert, \& Chavez, 1993; Chavez, 2002; Chavez \& Olson, 2009; Sasidharan et al., 2005), our findings begin to address the larger question of "Why do different groups visit and use parks in different ways?" (Byrne \& Wolch, 2009, p. 749). Interviewees see recreation as something done outside the home because, for most participants in this study, their home spaces do not have all of the qualities desired in a recreation location. Where their homes may lack scenery, seclusion, and suitability for larger family or group gatherings, the recreation sites they choose often maintain the characteristics of being close while having some desired facilities. Many interviewees, therefore, choose recreation sites similar to a "bigger backyard," or spaces to gather in which they can find the desired qualities in recreation locations they lack at home, likely due to socioeconomic status and the inability to purchase homes on the larger landscaped lots that have grown in prevalence in many areas of the United States, including in Cache Valley.

The results of this study also indicate some other important similarities among the Latino respondents regarding where they choose to recreate. Roughly half of the land in Cache County is federally owned and managed, designated either as national forest or wilderness areas (Cache County Agricultural Advisory Board, 2003). There are, therefore, far fewer municipal recreation sites compared to potential federal sites. However, municipal recreation sites, particularly city parks, are most commonly visited by these respondents, and federal sites are the least commonly 
visited. Despite their abundance, relatively few federal recreation sites have the gathering space characteristics for large groups preferred by participants, which include facilities, family suitability, scenery, and proximity to home. While these characteristics are not unique solely to municipal sites, they are characteristics shared consistently by all municipal sites in Cache Valley, which appears to account for why they attracted higher visitation by these respondents. Our findings further support those by Gómez and Malega (2007) that distance itself (or alone) is not a good predictor for Latino site choice-what matters are the benefits perceived by the potential site users. Many of these perceived benefits in our study relate to characteristics of the sites themselves, only one of which was "proximity to home."

It may seem contradictory for some respondents to prefer both developed facilities and scenery in a recreation location, as development can be considered an intrusion on scenery. Just as with the meaning of recreation, what these participants consider "scenery" may differ from the mainstreamed White perception. For nearly all the participants in this study, scenery and scenic views are not wild places, but rather outdoor spaces in which they can enjoy valued elements of nature while still accessing the other "backyard" benefits of various facilities for use by those in their family or other members of their recreation group. The concept of "seclusion" also may differ based on comparison to contexts at home. Smaller homes and larger family groups living together may restrict one's ability to "get away."

Other researchers have reported that Latinos are more collectivistic than European Americans (Walker, Deng, \& Dieser, 2005). If true, this collectivistic propensity for Latinos may contribute to the fact that despite the highly varied geography of recreation in Cache Valley, Utah, only three city parks stood out as those most often and commonly visited by study respondents. When asked how they learned about local recreation places, every participant stated they first learned of the locations they now visit by speaking to others. The role of social networks and word-of-mouth appears important among this immigrant community as members tell each other about places to recreate and invite each other to recreation events. This finding on the role of social networks is consistent with findings by Stodolska and Santos (2006) in a study of Mexican temporary migrants elsewhere in the U.S. And as Chavez and Olson (2009) pointed out, Latino visitors are likely to continue frequenting those places as well as tell others about them, which leads to increased use by that population of the same places.

In summary, our findings point to the need to consider recreation site choices as embedded in geographic and historical context, but in a manner that also acknowledges the agency of the individuals who choose where to recreate and how. And from a justice perspective, it is necessary to understand the nuanced connections between site preferences and the social and environmental equity dimensions of accessing and benefitting from public resources. This study begins to address some of the issues identified by Byrne and Wolch (2009). However, their larger call to consider how landscapes, including recreation landscapes, become racialized (and ethnically segregated) through a variety of processes and practices remains incompletely addressed here.

\section{Conclusions: The Justice Argument Reiterated}

This exploratory research utilized a unique perspective and recreation mapping activity, prompting different understanding, conceptualization, and interpretation of Latino recreation. Seeking and recognizing the participant-provided definition of recreation broadens the scope and understanding of what recreation means, and allows for the emergence of themes left unexplored by previous research. This study contributes to the theme of site specific characteristics driving recreation decisions-an area often overlooked in ethnic group recreation research. 
Research of non-dominant population recreation rarely attempts to spatially or geographically understand recreation spaces used by groups from the point of view of how they choose to recreate, but instead still often focuses on why they do not use certain places more frequented by majority populations.

This research can be used to help recreation agencies and managers better understand the recreation places most preferred by Latinos who constitute the fastest growing portion of the U.S. population, and how to manage the characteristics of those sites in order to meet the needs and expectations of those visitors. Everyone should have some leisure, but non-mainstreamed ethnic groups are among those for whom society historically does not provide so well (Broadhurst, 2001). The recreation managers in this study held the perception that the Latino population's recreation needs were presently being met and, as a result, they were not taking active measures to develop or facilitate Latino recreation. Greater recognition of how Latinos conceptualize, seek, and experience recreation activities can help managers work to avoid or eliminate the ways recreation spaces themselves can contribute to unequal usage of sites. Taylor (2000) posits that because managers (specifically wildland managers) often assume visitors will be White, they have historically managed those areas in a way benefiting only White users, which is a practice not appropriate in a multicultural society.

The findings from this research support the literature indicating that Latino recreation occurs more often in specific types of sites, but contributes a new interpretive perspective that can help recreation managers see beyond ethnic stereotypes. While city parks are popular recreation locations among Latinos, this study shows that recreation site choice among this population is diverse and, more importantly, is driven by specific preferences and decision factors. Understanding the reasons for recreation site selection is paramount to moving beyond simply emphasizing cultural differences to considering why many Latinos seek a "bigger backyard," and can help recreation professionals address larger questions about access and distribution of recreation resources.

If care is not taken in how recreation space is regulated and managed according to such characteristics as facilities, family accommodations, and scenery, the portion of the population for whom those characteristics are important will not be drawn to that space. However, as those recreationists seek out and gather in the spaces that do provide the characteristics shown to be important in this study, the risk of creating and reinforcing ethnic and racial boundaries increases. The field of environmental justice has primarily concerned itself with the uneven distribution of environmental pollution impacts by race. Now, however, efforts are being made to expand the concerns of environmental justice to include a focus on how natural resources are being managed and used in ways that lead to social (in)justice (Getches \& Pellow, 2002).

In this article, we argue that in order to achieve social justice we need to start from an understanding of recreation that allows for, acknowledges, and values difference. Once we achieve this greater understanding, we may still face a practical justice challenge-how do we value difference, manage for it, but not also end up with effectively segregated recreation spaces? Floyd (2007) articulated one goal for research on race and ethnicity in leisure - to "contribute to formation of social policies designed to foster constructive engagement and goodwill among different racial and ethnic communities" (p. 250). As Peters (2010) has argued, the ability of people from different ethnic backgrounds to come together in parks and other recreation spaces can be a first step towards better inter-group understanding.

The United States is increasingly growing in ethnic and cultural diversity, and management of leisure and recreation spaces should reflect this demographic change. The phrase " $t]$ he nation 
that works together must be merged with the nation that plays together" (Phillip, 2000, p. 123) articulates an overarching objective for future recreation management. Understanding the effect recreation spaces have in achieving this objective is a crucial step in the process, and attention to the subtle ways people view and use those spaces must not be overlooked. A critical first step is that recreation professionals and researchers re-conceptualize and re-interpret Latino recreation patterns in ways that help move managers away from a continued White-conformist bias which attempts to erase ethnic differences. Understanding participants' choices in a larger geography of recreation options and the meaning those recreation activities have for them can help recreation managers meet the needs of non-mainstreamed segments of the population and promote greater justice in recreational resource provision and management.

\section{References}

Arai, S., \& Kivel, D. (2009). Critical race theory and social justice perspectives on whiteness, difference(s) and (anti)racism: A fourth wave of race research in leisure studies. Journal of Leisure Research, 41, 459-470.

Baas, J., Ewert, A., \& Chavez, D. (1993). Influence of ethnicity on recreation and natural environment use patterns: Managing recreation sites for ethnic and racial diversity. Environmental Management 17, 523-29.

Blahna, D., \& Black, K. (1993). Racism: A concern for recreation resource managers? In P. Gobster (Ed.), Managing urban and high-use recreation settings (General Technical Report NC163, pp. 111-118). St. Paul, MN: U.S.D.A. Forest Service, North Central Forest Experiment Station.

Boone, C., Buckley, G., Grove, J., \& Sister, C. (2009). Parks and people: An environmental justice inquiry in Baltimore, Maryland. Annals of the Association of American Geographers, 99(4),767-787.

Broadhurst, R. (2001). Managing environments for leisure and recreation. New York: Routledge.

Bryant, B. (Ed.). (1995). Environmental justice: Issues, policies, and solutions. Washington, DC: Island Press.

Byrne, J., \& Wolch, J. (2009). Nature, race and parks: Past research and future directions for geographic research. Progress in Human Geography, 33(6), 743-765.

Bullard, R. (1994). Dumping in Dixie: Race, class, and environmental quality. Boulder, CO: Westview Press.

Bullard, R., Mohai, P., Saha, R., \& Wright, B. (2007). Toxic wastes and race at twenty 1987-2007: Grassroots struggles to dismantle environmental racism in the United States. Cleveland, $\mathrm{OH}$ : United Church of Christ Justice and Witness Ministry.

Carr, D., \& Chavez, D. (1993). A qualitative approach to understanding recreation experiences: Central American recreation on the national forests of southern California. In A. Ewert, D. Chavez, \& A. Magil (Eds.), Culture, conflict, and communication in the wildland-urban interface (pp. 181-194). Boulder, CO: Westview Press.

Carr, D., \& Williams, D. (1993). Understanding the role of ethnicity in outdoor recreation experiences. Journal of Leisure Research, 25, 22-38.

Chavez, D. (2000). Invite, include, and involve! Racial groups, ethnic groups, and leisure. In M. Allison \& I. Schneider (Eds.), Diversity and the recreation profession: Organizational perspectives (pp. 179-191). State College, PA: Venture. 
Chavez, D. (2001). Managing outdoor recreation in California: Visitor contact studies 1989-1998 (General Technical Report PSW-GTR-180). Albany, CA: U.S.D.A. Forest Service, Pacific Southwest Research Station.

Chavez, D. (2002). Adaptive management in outdoor recreation: Serving Hispanics in southern California. Western Journal of Applied Forestry, 17, 129-133.

Chavez, D., \& Olson, D. (2009). Opinions of Latino outdoor recreation visitors at four urban national forests. Environmental Practice, 11, 1-7.

Corbin, J., \& Strauss, A. (2007). Basics of qualitative research: Techniques and procedures for developing grounded theory (3rd ed.). Thousand Oaks, CA: Sage Publications.

Crawford, D., Jackson, E., \& Godbey, G. (1991). A hierarchical model of leisure constraints. Leisure Sciences, 13, 309-320.

Creswell, J. (2009). Research design: Qualitative, quantitative, and mixed-methods approaches ( $3^{\text {rd }}$ ed.). Thousand Oaks, CA: Sage.

Cronan, M., Shinew, K., \& Stodolska, M. (2008). Trail use among Latinos: Recognizing diverse uses among a specific population. Journal of Park and Recreation Administration, 26(1), $62-86$.

Erickson, B., Johnson, C., \& Kivel, B. D. (2009). Rocky Mountain National Park: History and culture as factors in African-American park visitation. Journal of Leisure Research, 41, $529-545$

Feagin, J. (2007). Racial and ethnic relations (8th ed.). Englewood Cliffs, NJ: Prentice Hall.

Floyd, M. (2007). Research on race and ethnicity in leisure: Anticipating the fourth wave. Leisure, 30(1), 245-254.

Floyd, M. (1998). Getting beyond marginality and ethnicity: The challenge for race and ethnic studies in leisure research. Journal of Leisure Research, 30, 3-22.

Floyd, M. (1999). Race, ethnicity, and use of the National Park System. NPS Social Science Research Review 1(2): 1-24.

Floyd, M., \& Gramann, J. (1993). Effects of acculturation and structural assimilation in resourcebased recreation: The case of Mexican Americans. Journal of Leisure Research, 25, 6-21.

Floyd, M., \& Johnson, C. (2002). Coming to terms with environmental justice in outdoor recreation: A conceptual discussion with research implications. Leisure Sciences, 24, 59-77.

Floyd, M., Spengler, J., Maddock, J., Gobster, P., \& Suau, L. (2008). Environmental and social correlates of physical activity in neighborhood parks: An observational study in Tampa and Chicago. Leisure Sciences, 30, 360-375.

Getches, D., \& Pellow, D. (2002). Beyond "traditional" environmental justice. In K. Mutz, C. Bryner, \& D. Kenney (Eds.), Justice and natural resources: Concepts, strategies, and applications (pp. 3-30). Washington: Island Press.

Glaser, B., \& Strauss, A. (1967). The discovery of grounded theory: Strategies for qualitative research. Chicago, IL: Aldine Publishing Company.

Gobster, P. (2002). Managing urban parks for a racially and ethnically diverse clientele. Leisure Sciences, 24, 143-159.

Gómez, E. (2002a). Puerto Ricans and recreation participation: Methodological, cultural, and perceptual considerations. World Leisure Journal, 44(2), 46-62.

Gómez, E. (2002b). The ethnicity and public recreation model. Leisure Sciences, 24, 123-142.

Gómez, E., \& Malega, R. (2007). Residential attributes, park use and perceived benefits: An exploration of individual and neighborhood characteristics. Leisure/Loisir, 31(1), 77-104.

Hall, M., \& Page, S. (2006). The geography of tourism and recreation: Environment, place and space ( $2^{\text {nd }}$ ed.). New York: Routledge. 
Hutchison, R., \& Fidel, K. (1984). Mexican-American recreation activities: A reply to McMillen. Journal of Leisure Research, 16, 344-349.

Joassart-Marcelli, P. (2010). Leveling the playing field? Urban disparities in funding for local parks and recreation in the Los Angeles region. Environment and Planning A, 42, 11741192.

Juniu, S. (2000). The impact of immigration: Leisure experience in the lives of South American immigrants. Journal of Leisure Research, 32, 358-382.

Kelly, J. (1999). Leisure behaviors and styles: Social, economic, and cultural factors. In E. Jackson, \& T. Burton (Eds.), Leisure studies: Prospects for the twenty-first century (pp. 135-150). State College, PA: Venture.

Li, C., Chick, G., Zinn, H., Absher, J., \& Graefe, A. (2007). Ethnicity as a variable in leisure research. Journal of Leisure Research, 39, 514-545.

Madsen, J., Radel, C., \& Endter-Wada, J. (2013). Unmet recreation desires or undesired recreation? A case study in access and custom in Hispanic/Latino recreation site choice. (Unpublished paper). Utah State University, Logan, UT.

Mannell, R. (2005). Evolution of cross-cultural analysis in the study of leisure: Commentary on "Culture, Self-Construal, and Leisure Theory Practice." Journal of Leisure Research, 37, 100-105.

McMillen, J. (1983). The social organization of leisure among Mexican-Americans. Journal of Leisure Research, 15, 164-173.

Mowatt, R. (2009). Notes from a leisure son: Expanding an understanding of whiteness in leisure. Journal of Leisure Research, 41, 509-526.

Neuman, W. L. (2009). Social research methods: Qualitative and quantitative approaches (7th ed.) . Boston: Allyn and Bacon, Pearson Education, Inc.

Parr, M., \& Lashua, B. (2004). What is leisure? The perceptions of recreation practitioners and others. Leisure Sciences, 26, 1-17.

Peters, K. (2010). Being together in urban parks: Connecting public space, leisure, and diversity. Leisure Sciences, 32(5), 418-433.

Phillip, S. (2000). Race and the pursuit of happiness. Journal of Leisure Research, 32, 121-124.

Roberts, N., \& Chitewere, T. (2011). Speaking of justice: Exploring ethnic minority perspectives of the Golden Gate National Recreation Area. Environmental Practice, 13(4), 1-16.

Roberts, N., \& Rodriguez, D. (2008). Use of multiple methods: An examination of constraints effecting ethnic minority visitor use of national parks and management implications. Ethnic Studies Review, 31(2), 35-70.

Sasidharan, V., Willits, F., \& Godbey, G. (2005). Cultural differences in urban recreation patterns: An examination of park usage and activity participation across six population subgroups. Managing Leisure, 10, 19-38.

Schneider, A. L., \& Ingram, H. (1997). Policy design for democracy. Lawrence, KS: University Press of Kansas.

Scott, D., Herrera, D., \& Hunt, K. (2004). Constraints to outdoor recreation among ethnic and racial groups. In D. Bengston (Chair), Identifying changing public land visitor needs and wants. Proceedings for the Fourth Social Aspects and Recreation Research Symposium, San Francisco, CA.

Scott, D., \& Kim, C. (1998). Outdoor recreation participation and barriers to involvement. In Texas outdoors: A vision for the future, A report to the Texas Parks and Wildlife Department, Austin, TX. Department of Recreation, Park, and Tourism Sciences, Texas A\&M University. 
Shinew, K., Stodolska, M., Floyd, M., Hibbler, D., Allison, M., Johnson, C., \& Santos, C. (2006). Race and ethnicity in leisure behavior: Where have we been and where do we need to go? Leisure Sciences, 28, 403-408.

Sister, C., Wolch, J., \& Wilson, J. (2010). Got green? Addressing environmental justice in park provision. GeoJournal, 75, 229-248.

Smith, S. (1983). Recreation geography. Harlow, UK: Longman Group Limited.

Stanis, S. W., Schneider, I., Chavez, D., \& Shinew, K. (2009). Visitor Constraints to Physical Activity in Park and Recreation Areas: Differences by Race and Ethnicity. Journal of Park and Recreation Administration, 27(3), 78-95.

Stodolska, M. (1998). Assimilation and leisure constraints: Dynamics of constraints on leisure in immigrant populations. Journal of Leisure Research, 30, 521-551.

Stodolska, M. (2000). Changes in leisure participation patterns after immigration. Leisure Sciences, 22(1), 39-63.

Stodolska, M., Acevedo, J. C., \& Shinew, K. J. (2009). Gangs of Chicago: Perceptions of crime and its effect on recreation behavior of Latino residents of urban communities. Leisure Sciences, $31,466-482$.

Stodolska, M., \& Alexandris, K. (2004). The role of recreational sport in the adaptation of firstgeneration immigrants in the United States. Journal of Leisure Research, 36, 379-413.

Stodolska, M., \& Santos, C. A. (2006). Transnationalism and leisure: Mexican temporary migrants in the United States. Journal of Leisure Research, 38, 143-167.

Stodolska, M., \& Walker, G. J. (2007). Ethnicity and leisure: Historical development, current status, and future directions. Leisure/Loisir, 31, 3-26.

Stodolska, M., \& Yi, J. (2003). Impacts of immigration on ethnic identity and leisure behavior of adolescent immigrants from Korea, Mexico and Poland. Journal of Leisure Research, 35(1), 49-79.

Taylor, D. (2000). Meeting the challenge of wild land recreation management: Demographic shifts and social inequality. Journal of Leisure Research, 32, 171-179.

United States Census Bureau. (2011a). American Factfinder fact sheet: Cache County, Utah. Retrieved from http://quickfacts.census.gov/qfd/states/49/49005.html

United States Census Bureau. (2011b). United States Hispanic population. Retrieved from http:// quickfacts.census.gov/qfd/states/00000.html

United States Census Bureau. (2008). Percent of the projected population by race and Hispanic origin for the United States: 2010 to 2050. Retrieved from http://www.census.gov/population/ projections/files/analytical-document09.pdf

U.S.D.A. Forest Service. (2010). National Visitor Use Monitoring Results: Wasatch-Cache National Forest. Retrieved from http://apps.fs.usda.gov/nrm/nvum/results/A04019.aspx/Round2

Walker, G., Deng, J., \& Dieser, R. (2005). Culture, self-construal, and leisure theory. Journal of Leisure Research, 37, 77-99.

Washburne, R. (1978). Black under-participation in wildland recreation: Alternative explanations. Leisure Sciences, 1, 175-189.

West, P. (1989). Urban region parks and black minorities: Subculture, marginality, and interracial relations in park use in the Detroit metropolitan area. Leisure Sciences, 11, 11-28.

Young, I. (2008). Structural injustice and the politics of difference. In G. Craig, T. Burchardt \& D. Gordon (Eds.), Social justice and public policy: Seeking fairness in diverse societies. (pp. 77-104). Bristol, UK: The Policy Press. 